\title{
A Molar Basis Comparison of Calcium Hydroxide, Sodium Hydroxide, and Potassium Hydroxide on the Pretreatment of Switchgrass and Miscanthus Under High Solids Conditions
}

\author{
Carla Inês Soares Rodrigues ${ }^{\mathrm{a}}$, Joshua J Jackson ${ }^{\mathrm{b}}$, Michael D Montross ${ }^{*}$
}

${ }^{a}$ Former graduate MS student at University of Kentucky, Biosystems and Agricultural Engineering Department, Lexington, KY, 40546-0276. Currently Ph.D. student at University of Campinas, Bioprocess and Metabolic Engineering Laboratory, Rua Monteiro Lobato, 80, 13083-062 Campinas - SP, Brazil,

${ }^{\mathrm{b}}$ Post-doctoral scholar, University of Kentucky, Biosystems and Agricultural Engineering Department, Lexington, KY, 40546-0276

*Corresponding author, professor University of Kentucky, Biosystems and Agricultural Engineering Department, 128 Barnhart Building, Lexington, KY 40546-0276, ph: +01-859-218-4319, email: michael.montross@uky.edu

\begin{abstract}
Pretreatment is an essential step in the formation of liquid biofuels. Switchgrass and miscanthus were pretreated using calcium hydroxide, potassium hydroxide, and sodium hydroxide at an equivalent hydroxyl concentration ( $0.46 \mathrm{~g} \mathrm{OH}^{-} / \mathrm{g}$ dry biomass), at a solids content of $40 \%$, and two temperatures $\left(25\right.$ and $\left.50{ }^{\circ} \mathrm{C}\right)$ for seven days. The cellulose, hemicellulose, and lignin composition before and after pretreatment were quantified according to the standard procedures developed by the National Renewable Energy Laboratory. After pretreatment, enzyme hydrolysis was performed at $50{ }^{\circ} \mathrm{C}$ in a shaking
\end{abstract}


incubator with an enzyme loading of $60 \mathrm{FPU} / \mathrm{g}$ cellulose. Potassium and sodium hydroxide led to the largest reduction in lignin of between 30 to $47 \%$ with the two feedstocks and two temperature levels. Calcium hydroxide had a significantly lower amount of delignification of between 13 to $21 \%$. Sodium and potassium hydroxide had a similar maximum reaction rate, except for switchgrass pretreated at $50{ }^{\circ} \mathrm{C}$ where the reaction rate was lower for potassium hydroxide. Cellulose conversion was the highest for sodium and potassium hydroxide and varied between 56.1 and $80.5 \%$ for both feedstocks at the two pretreatment temperatures investigated. Calcium hydroxide demonstrated a significantly lower cellulose conversion that varied between 23.0 and $44.9 \%$. The results indicated that with an equivalent molar basis of $\mathrm{OH}^{-}$, potassium and sodium hydroxide had superior performance relative to calcium hydroxide in a high solids environment.

Keywords: Alkaline Pretreatment, Enzymatic Hydrolysis, Dedicated Energy Crops, Molar Basis, High Solids 


\section{INTRODUCTION}

Lignocellulose biomass pretreatment is a fundamental step in the production of renewable fuels as the conversion of cellulose into fermentable monomers is enhanced by the cleavage of lignin and hemicellulose (Kumar et al., 2009). A number of different pretreatment methods exist, but alkaline pretreatment demonstrates many desirable qualities with low energy and temperature requirements for reactions which makes alkaline pretreatment desirable as a potential low-severity, pretreatment option. The alkalinity of sodium hydroxide $(\mathrm{NaOH})$, potassium hydroxide $(\mathrm{KOH})$, and calcium hydroxide $\left(\mathrm{Ca}(\mathrm{OH})_{2}\right)$ weakens the intermolecular hydrogen bonds between cellulose, and this creates swelling (Baral et al., 2013). The swelling allows for more accessibility to the cellulose structure by increasing the surface area while reducing cellulose crystallinity and the degree of polymerization. Furthermore, the lignin, hemicellulose, and silica are dissolved by hydrolyzing the acetyl moieties attached to hemicellulose (Jackson, 1977). The rate of delignifcation is influenced by the concentration of hydroxide ions and overall $\mathrm{pH}$ (Dolk et al., 1989).

Numerous hydroxides have been studied for alkaline biomass pretreatment, but sodium hydroxide (Nlewem and Thrash Jr, 2010; Silverstein et al., 2007; Varga et al., 2002), potassium hydroxide (Bales et al., 1979; Ong et al., 2010; Sharma et al., 2013), and calcium hydroxide (Kaar and Holtzapple, 2000; Sirohi and Rai, 1998; Xu et al., 2010a) are the most common with sodium hydroxide being the most extensively studied. For the differing alkaline pretreatment options, the physical/chemical composition of the biomass and pretreatment conditions (chemical used, chemical concentration, moisture content, 
temperature, $\mathrm{pH}$, and duration of pretreatment) are influential in determining the final yields of glucose available to be transformed into products (Chen et al., 2013).

The physical and compositional characteristics of biomass varies with the crop. The use of dedicated biomass crops such as Miscanthus x giganteus and Panicum virgatum (generically referred to as miscanthus and switchgrass in this study) is becoming ever more important as these crops manifest high yields, resilience in production on marginal land and at various climates, and low fertilizer/pesticide inputs (Heaton et al., 2008; Samuel et al., 2011). For these crops, hemicellulose and lignin can make up $45 \%$ of the weight on a dry basis (Brown, 2003). Therefore, the solubilization of these polymers is important to increase the cellulose available to the degrading enzymes. Solubilization is directly related to lignin and hemicellulose removal from the lignocellulosic matrix.

With regard to pretreatment conditions, inherent tradeoffs exist for the differing hydroxide pretreatments with each possessing positive and negative attributes related to hydrolysis effectiveness, cost, ability to recover/recycle, caustic nature, and environmental impact (Chen et al., 2013). When the pretreatment effectiveness of potassium and sodium hydroxide were compared, opinions varied. Bales et al. (1979) reported that $\mathrm{NaOH}$ applied at $0.05 \mathrm{~g} / \mathrm{g} \mathrm{DM}$ on milo stalks appeared superior to potassium hydroxide at the equivalent concentration, despite disadvantages associated with sodium related to animal and soil toxicity. Ong et al. (2010), on the other hand, showed that higher cellulase production was achieved with rice straw treated with potassium hydroxide than with samples treated with sodium hydroxide after solid state fermentation with $1 \times 10^{-7} \mathrm{~mL}^{-1}$ spores of Aspergillus niger. 
Many researchers have concluded that calcium hydroxide is not as effective of a pretreatment agent as other alkalis such as sodium and potassium hydroxide (Chang et al., 1997). Nonetheless, calcium hydroxide possess many desirable qualities for pretreatment from many aspects. Firstly, the cost of calcium hydroxide is the lowest of the hydroxides typically used for biomass pretreatment $\$ 0.10 / \mathrm{kg} \mathrm{Ca}(\mathrm{OH})_{2}$ versus $\$ 0.36 / \mathrm{kg}$ sodium hydroxide and \$3.78/kg potassium hydroxide (Kaar and Holtzapple, 2000). Furthermore, the calcium can be recovered by adding $\mathrm{CO}_{2}$ to the solution and precipitating calcium carbonate $\left(\mathrm{CaCO}_{3}\right)$ out of solution. Compared to the other alkalis, calcium hydroxide is safer to handle (Davidson, 1927) whereas sodium and potassium hydroxide possess a more caustic nature (Davidson, 1927).

In a direct comparison of sodium, potassium, and calcium hydroxide, Yang (2009) showed that after 24 hours of pretreatment, $\mathrm{NaOH}$ at a $10 \%$ concentration was the most effective pretreatment for the production of biogas. In this trial, $\mathrm{NaOH}$ removed the most lignin overall, and at each concentration level (5\%, 10\%, and 15\%), $\mathrm{NaOH}$ removed more lignin than the other hydroxide treatments. However, the short pretreatment time period (24 hours) favors $\mathrm{NaOH}$ compared to $\mathrm{Ca}(\mathrm{OH})_{2}$ which performed the poorest. Calcium hydroxide would need more time for delignification and increased sugar yield to take place. With a 24 hour pretreatment duration, the in vitro dry matter digestibility of corn cobs was demonstrated to be equivalent $(\sim 75 \%)$ for sodium and potassium hydroxide at $0.05 \mathrm{~g} / \mathrm{g} \mathrm{DM}$ but $\mathrm{Ca}(\mathrm{OH})_{2}$ was deemed to be ineffective at $\sim 62 \%$ (Rounds et al., 1976).

Most of these comparisons were made considering a combination of treatments using calcium, sodium and potassium hydroxides under the same conditions, specifically 
using the same amount of chemical on a weight basis. However, this is an imbalanced comparison as sodium, potassium, and calcium hydroxide possess differing $\% \mathrm{OH}$ concentrations as shown in Table 1. Furthermore, calcium hydroxide is a weaker base and to achieve an equivalent alkalinity requires eight times as much calcium hydroxide as sodium hydroxide (Winugroho et al., 1984). For potential on-farm processing, a moderate temperature range $\left(25-50{ }^{\circ} \mathrm{C}\right)$ would be desirable and similar temperature ranges have been used in other trials (Kim and Holtzapple, 2005).

Another complicating issue is the solids content during pretreatment. Most studies have utilized a low solids loading rate that aids pretreatment; however, there are numerous advantages to high solids systems including higher sugar yields and lower costs (Modenbach and Nokes, 2012). Chen et al. (2013) investigated the lignin removal from corn stover pretreated at solids loadings of 5, 10, and 15\% and found minimal differences. A proposed on-farm solid-state conversion system would utilize high density, baled biomass feedstocks in a modified bunker system (Nokes et al., 2014). Pretreatment under high solids contents (greater than 30\%) that could be expected using baled biomass has not been extensively studied, although pretreatment studies of crop residues with solid-state anaerobic digesters would be similar. Ge et al. (2016) reviewed solid-state anaerobic digestion and reported that alkaline pretreatments of crop residues was effective at increasing the biogas yield at solids contents greater than $20 \%$.

Undigested solid biomass and byproducts of pretreatment could be reapplied to the land and utilized for the production of additional lignocellulosic materials. The disposal of the undigested biomass would be complicated by the formation of salts resulting from 
alkaline pretreatment (Zheng et al., 2009). This project is focused on investigating techniques that could be applicable to distributed, on-farm processing. With regard to pretreatment with sodium, potassium, and calcium hydroxide, calcium and potassium are macronutrients required for soil fertility and land application of these nutrients for crop production is common. Whereas, the land application of residual sodium would result in the accumulation of salts.

An experiment comparing calcium, sodium, and potassium hydroxides on a molar basis would contribute to a better understanding of their pretreatment effectiveness. For this reason, this study aimed to develop comparative technical information on the alkaline pretreatment of miscanthus and switchgrass and the subsequent enzyme hydrolysis of sodium, potassium, and calcium hydroxide on a constant molar basis under high solids conditions.

\section{MATERIALS AND METHODS}

\subsection{Biomass Preparation}

Harvesting, storage, and grinding of Alamo switchgrass (Panicum virgatum L.) and miscanthus (Miscanthus x giganteus) was conducted as described by Jackson et al. (2016) with some modifications. The biomass was ground through a $5 \mathrm{~mm}$ round hole screen using a No. 20 hammer mill (C.S. Bell Co., Tiffin, OH) with further grinding through a $2 \mathrm{~mm}$ square hole screen conducted using a knife mill (Retsch GmbH, type SM1 \# 70947). Following grinding, the material was dried at $44.5 \pm 0.2^{\circ} \mathrm{C}$ for 48 hours, and cooled at room temperature $25^{\circ} \mathrm{C}$ for 24 hours. After cooling, the ground samples were stored in zipper plastic bags and placed in a refrigerator at $4^{\circ} \mathrm{C}$ until further testing. 


\subsection{Pretreatment}

Twenty-four samples of ten grams (dry matter) of each biomass were placed in autoclaved $250 \mathrm{ml}$ Erlenmeyer flasks. Distilled water was added to each flask to achieve a $40 \%$ solids content ( $1.5 \mathrm{ml}$ water/g dry biomass). The flasks were randomly separated into two groups of twelve for pretreatment at two temperature levels $\left(20\right.$ and $\left.50{ }^{\circ} \mathrm{C}\right)$ and agitated at $150 \mathrm{rpm}$. The flasks at each temperature level were again divided into four subgroups: three were pretreated with the different sources of hydroxyl (calcium hydroxide, sodium hydroxide, and potassium hydroxide) and one control (distilled water added). Previous research has indicated that an ideal loading rate was $0.1 \mathrm{~g} \mathrm{chemical}^{*} \mathrm{~g} \mathrm{biomass}^{-1}$ (Chang et al., 1997; Cheng et al., 2010). Thus, $1 \mathrm{~g}$ of calcium hydroxide is required per each $10 \mathrm{~g}$ biomass that results in an equivalent hydroxide concentration of $0.46 \mathrm{~g} \mathrm{OH}^{-} / \mathrm{g} \mathrm{DM}$ biomass. This loading rate was used for the other chemicals that resulted in $0.100,0.151$, and $0.108 \mathrm{~g}$ of pretreatment chemical per gram of dry matter for calcium, potassium, and sodium hydroxide, respectively. The pretreatments were conducted for seven days.

After pretreatment, the biomass was washed with distilled water until the $\mathrm{pH}$ was between 7 and 8 . Subsequently, the solids were dried at $44.5^{\circ} \mathrm{C} \pm 0.2$ for 48 hours, left at room temperature for 24 hours, stored in zipper plastic bags, and placed into refrigerator at $4{ }^{\circ} \mathrm{C}$.

\subsection{Biomass Characterization}

Untreated (raw) and pretreated materials were prepared in triplicate and the composition of cellulose, hemicellulose, acid soluble lignin, acid insoluble lignin, and ash 
measured following the National Renewable Energy Laboratory (NREL) Analytical

Procedure "Determination of Structural Carbohydrates and Lignin in Biomass" (2012) using unextracted samples. Samples were analyzed in duplicate by HPLC using a Bio-Rad Aminex HPX-87H (order \#125-0140) (ion exclusion) column at $50{ }^{\circ} \mathrm{C}$ with $0.40 \mathrm{~mL} \mathrm{~min}{ }^{-1}$ flow rate and a 5 mM sulfuric acid (Fisher \#AC124645001) mobile phase. Chromeleon 7.1 software processed the HPLC data. Glucose and xylose were the only structural carbohydrates measured. The mass balance was determined by summing the average composition of each component and the mass balance standard deviation was calculated by taking the square root of the sum of the variance of the individual components.

\subsection{Enzymatic Activity and Hydrolysis}

Cellulase was obtained from American Laboratories Incorporated (Lot \# ALI 14175-04). The cellulase activity was determined according to the NREL Laboratory Analytical Procedure (LAP) "Measurement of Cellulase Activities" (006, 1996) and expressed in terms of filter paper units (FPU).

Enzymatic hydrolysis was carried out in $125 \mathrm{ml}$ Erlenmeyer flasks. Samples of each pretreated biomass that corresponded to $0.5 \mathrm{~g}$ of cellulose were added to six flasks to allow for triplicate measurements, including controls for each pretreated biomass. Untreated biomass was also enzymatically hydrolyzed as a control. The hydrolysis liquid was prepared with a $50 \%$ volume of $0.1 \mathrm{M}$ sodium citrate buffer, $1 \%$ volume of $2 \%$ sodium azide solution, and the remainder was distilled water to complete a final $50 \mathrm{~mL}$ volume of hydrolysis liquid. All solutions and the substrates were assumed to have a specific density of $1.0 \mathrm{~g} / \mathrm{mL}$. The $\mathrm{pH}$ of the samples with the hydrolysis liquid was measured in order to 
verify that the $\mathrm{pH}$ was $5 \pm 0.2$ which was the ideal $\mathrm{pH}$ required to perform the enzymatic hydrolysis. The flasks were sealed, and placed into a shaker at $150 \mathrm{rpm}$ for 72 hours at 50 ${ }^{\circ} \mathrm{C}$. The enzyme loading was $60 \mathrm{FPU} / \mathrm{g}$ cellulose.

The influence of residence time on the hydrolysis of the different pretreated biomass samples was evaluated by collecting $1.2 \mathrm{~mL}$ aliquots of the reaction liquid at sampling times of $0,1,3,6,12,24,36,48,60$, and $72 \mathrm{~h}$. Microcentrifuge tubes containing the aliquots were then immersed in boiling water for $15 \mathrm{~min}$ to stop the reaction. The pellet was sedimented through double centrifugation at 10,000 rpm for $15 \mathrm{~min}$, and the supernatant was analyzed in duplicate by HPLC for glucose and xylose content as described in previous section.

\subsection{Statistical Analysis}

All treatments in this study were conducted in triplicate. The experimental design was balanced and completely randomized. SAS 9.3 software was used to perform analysis of variance (ANOVA) on the experimental results to analyze the statistical significance of the data at a $95 \%$ confidence level. ANOVA was also used to verify the effect of the treatment factors (pretreatment agent and temperature) on the response variables (lignin, carbohydrates, ash, reaction rate, and cellulose conversion rate). Significance was evaluated using Tukey's correction test at a level of significance of $5 \%$.

\section{RESULTS AND DISCUSSION}

\subsection{Effect of Pretreatment on Biomass Composition}


The effectiveness of pretreatment was assessed by measuring compositional changes and enzymatic hydrolysis. The change in biomass composition both prior and subsequent to pretreatment has been used to access the reduction in lignin and improved characteristics for cellulose breakdown (Modenbach and Nokes, 2012) and was used to evaluate the effectiveness of the pretreatment. The average composition and standard deviation of unextracted raw miscanthus and switchgrass used in this project are shown in Table 2. With raw, unextracted biomass, $98 \%$ of the composition mass balance was quantified for switchgrass and miscanthus. The composition of the raw biomass used in this study was similar to other literature results. In research conducted by (Sharma et al., 2013), the carbohydrate and total lignin (acid soluble and acid insoluble) portions of switchgrass were estimated to be $67.3 \%$ and $24.7 \%$, respectively which was comparable to $67.2 \%$ carbohydrates and $29.8 \%$ lignin reported in this study. For miscanthus, this work showed that $65.3 \%$ and $32.2 \%$ of total biomass was attributed to carbohydrates and total lignin, respectively. These results are in accordance to the $62.5 \%$ of carbohydrates reported by (de Vrije et al., 2002), although there was a mismatch for the lignin content since the lignin used in their work corresponded to only $25 \%$ of total biomass composition.

The results indicated that the three alkaline pretreatments applied (calcium hydroxide, sodium hydroxide and potassium hydroxide) to the two feedstocks (switchgrass and miscanthus) at both temperatures $\left(20\right.$ and $\left.50{ }^{\circ} \mathrm{C}\right)$ created some differences in the composition between raw and pretreated biomass. Although, the controls that were pretreated with water also had some influence on the change in composition depending on 
the feedstock and temperature. This was likely due to the use of unextracted biomass samples.

Most pretreatments have been developed under low-solids conditions, where pretreatments are most effective (Modenbach and Nokes, 2012). This study utilized high solids ( $40 \%$ dry matter content) that likely reduced the effectiveness of the pretreatments relative to other literature data. This was done to aid in the development of on-farm biomass processing systems where a high solids content is desirable.

\subsubsection{Lignin Changes Due to Pretreatment}

When compared to the raw untreated material (switchgrass or miscanthus), the use of chemical pretreatments resulted in reductions of $13 \%$ to $48 \%$ in the lignin content (Figs. 1 and 2). For switchgrass, the lignin composition response to the chemical treatments was statistically equivalent at 20 and $50{ }^{\circ} \mathrm{C}$. For sodium and potassium hydroxide pretreated switchgrass, the lignin content was equivalent and resulted in the largest $(P \leq 0.05)$ reduction (30 to 37\%) in lignin when compared to the raw material. Calcium hydroxide pretreated switchgrass significantly decreased lignin by (13 to $21 \%$ ) when compared to the raw biomass.

For miscanthus, the reduction in lignin with calcium hydroxide was the least efficient among the three alkaline compounds evaluated. While being significantly different than the raw miscanthus, calcium hydroxide pretreated miscanthus at $20{ }^{\circ} \mathrm{C}$ manifested an equivalent lignin content to the control that had been pretreated with water. Miscanthus showed a statistically significant delignification at $50{ }^{\circ} \mathrm{C}$ between calcium hydroxide and that which had been treated with water. Potassium and sodium hydroxide were not 
signficantly different from each other at their respective temperature and resulted in a reduction of lignin of 32 to $35 \%$ at $20{ }^{\circ} \mathrm{C}$ and 45 to $47 \%$ at $50{ }^{\circ} \mathrm{C}$.

Potassium and sodium hydroxide performed similiarly in this study, that matched previous studies. Anderson and Ralston (1973) found that there was no difference in delignification between sodium and potassium hydroxide when pretreating rye straw with $0.3 \mathrm{~g}$ of chemical/g biomass for $48 \mathrm{~h}$ at room temperature. (Bales et al., 1979) found that $\mathrm{NaOH}$ and $\mathrm{KOH}$ had an equivalent effect in terms of delignification on a molar basis on milo stalks.

Calcium hydroxide features low alkalinity and solubility in water (Chang et al., 1997). Calcium hydroxide solubility is 0.173 and 0.133 grams in $100 \mathrm{ml}$ of water at $20{ }^{\circ} \mathrm{C}$ and $50{ }^{\circ} \mathrm{C}$, respectively. Potassium hydroxide and sodium hydroxide, in comparison, solubilize, respectively, 117.4 and 111.0 grams in $100 \mathrm{ml}$ of water at $20{ }^{\circ} \mathrm{C}$ and, 138.3 and 106.4 grams at $50{ }^{\circ} \mathrm{C}$. Because of calcium hydroxide's solubility, it has been surmised that samples treated with this alkali require longer residence time to achieve the same lignocellulose digestibility rate as samples treated with either sodium (Winugroho et al., 1984) or potassium hydroxides. In the interest of lignin reduction specifically, under alkaline conditions, calcium ions tend to link to lignin forming a calcium-lignin complex, which prevents an intense lignin solubilization during pretreatment ( $\mathrm{Xu}$ et al., 2010a). The time and solids content of the pretreatment conditions in this study likely limited the delignification observed with biomass pretreated with calcium hydroxide. 


\subsubsection{Cellulose Changes Due to Pretreatment}

A varied effect due to chemical pretreatment was observed with the alkaline chemical pretreatments used at the two temperatures. With switchgrass pretreated at $50{ }^{\circ} \mathrm{C}$, all the alkaline hydroxide pretreatments were statistically equivalent but resulted in an increased (16 to $42 \%$ ) cellulose content when compared to the raw and water treated switchgrass. Similarly, miscanthus pretreated at $20{ }^{\circ} \mathrm{C}$ demonstrated no significant difference among the chemical pretreatments, while being significantly increased (27 $50 \%$ ) when compared to the raw and water pretreated miscanthus. At the higher temperature, calcium hydroxide pretreated miscanthus was not significantly different from that of the raw or water pretreated miscanthus. Sodium and potassium hydroxide pretreated miscanthus at $50{ }^{\circ} \mathrm{C}$ were significantly increased when compared to the raw material and resulted in the largest change in cellulose content after pretreatment (Figs. 1 and 2). In the case of cellulose, the concentration in the pretreated solids increased after pretreatment.

Increased cellulose composition from alkaline pretreatment in switchgrass has been observed and was stated to be the result of a reduction in lignin (Karp et al., 2015). Increasing the temperature form $100{ }^{\circ} \mathrm{C}$ to $160{ }^{\circ} \mathrm{C}$ increased the cellulose and hemicellulose content. Calcium hydroxide in most cases had similar performance to sodium and potassium hydroxide in increasing cellulose content, with the exception of miscanthus pretreated at $50{ }^{\circ} \mathrm{C}$.

\subsubsection{Hemicellulose Changes Due to Pretreatment}

With the exception of switchgrass pretreated at $50{ }^{\circ} \mathrm{C}$ and $\mathrm{NaOH}$ pretreated miscanthus at $20^{\circ} \mathrm{C}$, the change in hemicellulose content for the two biomass types 
analyzed due to alkaline hydroxide pretreatment was not significant different from the raw material at the respective temperature (Figs. 1 and 2). Nonetheless, the switchgrass pretreated at $50{ }^{\circ} \mathrm{C}$ showed that all of the alkaline chemical pretreatments were not significantly different from each other or the water pretreatment.

\subsubsection{Temperature Effect on Pretreatment of Switchgrass}

No temperature influence was observed in the change in lignin content of switchgrass (Fig. 1). Cellulose and hemicellulose content were significantly increased when the pretreatment temperature was $50{ }^{\circ} \mathrm{C}$ for all pretreatments investigated.

The numerically highest quantities of cellulose were attained at a pretreatment temperature of $50^{\circ} \mathrm{C}$. The increase in cellulose content was not significantly different for the three chemicals. However, the cellulose content was increased by approximately 15 percentage points over the raw material. (13 percentage points) occurred with calcium hydroxide. Changes in hemicellulose were unexpected. Unexpectedly, there were increases in the hemicellulose content with switchgrass pretreated at $50^{\circ} \mathrm{C}$.

\subsubsection{Temperature Effect on Pretreatment of Miscanthus}

For miscanthus, the pretreatment temperature had a statistically significant influence in delignification for all three alkali conditions investigated (Fig. 2). As expected, the lignin content decreased with the three chemicals when the temperature was increased. In terms of cellulose content, sodium and potassium hydroxide had a statistically significant increase in cellulose content as the temperature increased. At a temperature of $50{ }^{\circ} \mathrm{C}$, the cellulose content decreased relative to $20^{\circ} \mathrm{C}$ when pretreated with calcium hydroxide. 
Significant changes in hemicellulose content due to temperature differences were observed with sodium and potassium hydroxide samples. With the sodium and potassium hydroxide pretreatment at $50{ }^{\circ} \mathrm{C}$ led to an 8 and 7 percentage point decrease in hemicellulose relative to $20^{\circ} \mathrm{C}$. No significant changes in quantities of hemicellulose were noticed in calcium hydroxide pretreated miscanthus.

The majority of the results obtained in this study did not show a significant difference in delignification due to pretreatment temperature. The results obtained with this study did not follow the trend observed by other researchers. One possible reason for this may be due to the lower alkali loading utilized in this study, the higher solids content in this study, and the influence of pretreatment time.

The effect of pretreatment temperature on the cellulose and hemicellulose changes were expected to follow the trend observed for delignification. Removal of lignin has a direct influence on the cellulose and hemicellulose available in the pretreated solids (Modenbach and Nokes, 2012; Mosier et al., 2005). The measured results, however, showed a mixed trend. One plausible explanation for that lies in the loss of solids during pretreatment, which could skew the composition results. It was impossible to recover all of the biomass solids after pretreatment. The chemical composition of the solids lost when transferring between flasks and the soluble material removed during washing were not quantified.

\subsubsection{Dry Matter Losses from Pretreatment}

For switchgrass and miscanthus, the neutralization of the alkaline $\mathrm{pH}$ for subsequent enzyme hydrolysis was conducted by flushing the biomass material with distilled water 
until the $\mathrm{pH}$ was between 7 and 8 . Across the different alkaline hydroxide pretreatments, the dry matter retained after pretreatment and washing accounted for an average of 58 to $71 \%$ for switchgrass and demonstrated no significant difference among the pretreatments (Fig. 3). For miscanthus, calcium hydroxide at $20{ }^{\circ} \mathrm{C}$ possessed a dry matter loss of $20 \%$ and was significantly lower than 33 to $36 \%$ loss experienced by sodium hydroxide at both temperature and potassium hydroxide at $50{ }^{\circ} \mathrm{C}$.

\subsection{Enzymatic Hydrolysis of Pretreated Biomass}

Ultimately, the enzyme hydrolysis after pretreatment is a metric that can be used to provide an indicator of pretreatment effectiveness. The effectiveness of hydrolysis was evaluated by calculating the maximum reaction rate observed during hydrolysis and the percentage of cellulose converted into monomeric sugars.

\subsubsection{Enzymatic Hydrolysis Profile}

A complete hydrolysis profile was measured for both feedstocks with the pretreatment conditions investigated. Plots of cellulose conversion as a function of time are shown in Fig. 4. The cellulose digested is the mean of three replications. In Fig. 4a, the cellulose conversion at $72 \mathrm{~h}$ was not reported with calcium hydroxide due to contamination issues. It can be inferred from Fig. 4 that the cellulose digested during enzymatic hydrolysis varied in a similar manner as the delignification observed during pretreatment. Sodium and potassium hydroxide had the largest change in lignin concentration and in general the highest cellulose conversion over time. Pretreatment with calcium hydroxide led to a lower cellulose digestion over time relative to the sodium and potassium hydroxide, but was considerably higher than the raw or water treated biomass. 


\subsubsection{Maximum Cellulose Digestibility Reaction Rate}

The maximum cellulose digestion reaction rate, expressed in terms of g glucose $\mathrm{L}^{-1}$ $\mathrm{h}^{-1}$, was calculated by applying the Michaelis-Menten model for a batch reactor. As expected the maximum reaction rate was very low for the raw and water pretreated material at the two temperatures for both biomass types (Fig. 5). For switchgrass pretreated at $20^{\circ} \mathrm{C}$, there was no statistical difference between sodium and potassium hydroxide. Calcium hydroxide had a statistically lower reaction rate, about $50 \%$, compared to sodium hydroxide. For switchgrass pretreated at $50{ }^{\circ} \mathrm{C}$, sodium hydroxide had the highest reaction rate of the three chemicals. Potassium and calcium hydroxide had a 50 and $82 \%$ lower reaction rate, respectively.

Miscanthus pretreated at $20{ }^{\circ} \mathrm{C}$ with sodium and potassium hydroxide were not statistically different (Fig. 5). Calcium hydroxide was significantly lower, approximately $75 \%$ and $82 \%$ lower than sodium and potassium hydroxide, respectively. When miscanthus was pretreated at $50{ }^{\circ} \mathrm{C}$ the maximum reaction rate for sodium and potassium hydroxide were not statistically different and were higher than miscanthus pretreated at $20^{\circ} \mathrm{C}$. Calcium hydroxide had a $97 \%$ slower maximum reaction rate than sodium hydroxide at 50 ${ }^{\circ} \mathrm{C}$.

In most scenarios, the hydrolysis reaction rate of switchgrass and miscanthus pretreated with sodium hydroxide or potassium hydroxide were not significantly different (Fig. 5Error! Reference source not found.). Increased pretreatment temperatures increased the maximum reaction rate for sodium and potassium hydroxide, with the exception of switchgrass pretreated with potassium hydroxide. Samples pretreated with 
calcium hydroxide resulted in the lowest hydrolysis reaction rate among the alkaline pretreated samples. Unexpectedly, calcium hydroxide had a lower maximum reaction rate when the pretreatment temperature was increased.

The trend observed for maximum reaction rate from the two feedstocks suggested a relationship between delignification rate and hydrolysis reaction rate for all circumstances analyzed. This relationship followed the conventional wisdom on the role of pretreatment (Modenbach and Nokes, 2012; Mosier et al., 2005). With the breakage of the linkages in the lignocellulosic matrix, and the release of the lignin barrier, more cellulose is free to be easily accessed by the enzymes, and so, a faster, conversion occurred.

Results from this study had a similar trend in reaction rate as (Chang et al., 1997). Chang et al. (1997) concluded that since calcium hydroxide led to lower reaction rates than sodium and potassium hydroxides, a lower conversion was expected for samples pretreated with calcium hydroxide.

\subsubsection{Carbohydrate Conversion}

The percentage of polysaccharides converted into monosaccharides was another method used to evaluate the efficiency of a pretreatment and the success of a bioconversion process. Fig. 6 summarizes the percentage of cellulose converted for both switchgrass and miscanthus at the two temperatures with the three chemicals investigated in this study. Two controls were utilized; raw feedstock and feedstock pretreated with water. Due to contamination issues, the cellulose conversion for switchgrass pretreated with calcium hydroxide at $20^{\circ} \mathrm{C}$ was reported at 60 hours instead of 72 hours. 
Cellulose conversion varied between 56.1 and $70.5 \%$ when switchgrass was pretreated with either sodium hydroxide or potassium hydroxide at the two temperature levels. While calcium hydroxide was significantly lower with a cellulose conversion efficiency between 38.9 and $44.9 \%$. Increasing the pretreatment temperature had a minor effect. The only significant effect of increasing the pretreatment temperature was a decrease in cellulose converted with potassium hydroxide with switchgrass. This matched the decline in the maximum reaction rate observed for switchgrass pretreated at $50{ }^{\circ} \mathrm{C}$ compared to $20{ }^{\circ} \mathrm{C}$ with potassium hydroxide. In Fig. 5 there was a decrease in the maximum reaction rate for switchgrass pretreated at $50{ }^{\circ} \mathrm{C}$, however this did not influence the final cellulose conversion. The other pretreatments (raw, water, calcium and sodium hydroxide) had no statistical significant difference when the temperature was increased.

Overall, the cellulose conversion for miscanthus with sodium and potassium hydroxide varied between 59.0 and $80.5 \%$; calcium hydroxide was significantly lower and varied between 23.0 and $32.0 \%$ (Fig. 6). Increased pretreatment temperature significantly increased the cellulose conversion efficiency with sodium and potassium hydroxide. However, the increased temperature negatively impacted the cellulose conversion with calcium hydroxide. The overall cellulose conversion for miscanthus matched the trends observed for the maximum reaction rate shown in Fig. 5.

The cellulose converted in this study was similar to the carbohydrate conversions found by Xu et al. (2010a), Sharma et al. (2013), and Xu et al. (2010b), who also reported different performances with calcium hydroxide, potassium hydroxide, and sodium hydroxide, respectively, for similar hydrolysis conditions. However, looking at those 
studies, potassium hydroxide appeared to have the best performance. When equal hydroxide levels were used, the only significant difference observed between sodium and potassium hydroxide were in switchgrass at $50^{\circ} \mathrm{C}$.

Glucose yields from untreated switchgrass and switchgrass pretreated with lime for $2 \mathrm{~h}$ at $120{ }^{\circ} \mathrm{C}$ were 12.3 and $58.0 \%$, respectively (Chang et al., 1997). The yields from the water control and calcium hydroxide pretreatment in this study were approximately $50 \%$ lower. This could have been due to inhibitors in the pretreatment solution, differences in enzymes (loading, activity, types of enzymes, etc.), and differences in pretreatment conditions (solids content, time, and temperature).

A number of other factors influence the optimal choice of pretreatment chemicals and conditions. This study utilized a high solids content that likely reduced the pretreatment effectiveness of all three chemicals investigated (Modenbach and Nokes, 2012). The overall project goal is to process biomass into a crude butanol stream using a high-solids, on-farm system that would lower biomass transportation costs and increase farm income (Nokes et al., 2014). Alkaline pretreatment has been extensively studied for on-farm application to improve animal feed efficiency (Jackson, 1977) and would appear to be suitable for the proposed project (Nokes et al., 2014). Sodium and potassium hydroxide provided similar cellulose conversion rates, but sodium hydroxide is approximately half the cost of potassium hydroxide (Table 1 ). 
Table 3 summarizes the cost of pretreatment chemical only on the glucose produced using the conditions in this study. Sodium hydroxide in general resulted in the lowest cost sugar production ( $\$ 0.11$ to $0.19 / \mathrm{kg}$ of glucose) due to its high cellulose conversion and low chemical cost. Calcium hydroxide resulted in a slightly higher glucose cost, between $\$ 0.18$ to $0.45 / \mathrm{kg}$ of glucose, which was directly related to the lower cellulose conversion observed in this study. Potassium hydroxide resulted in the highest glucose cost of $\$ 0.45$ to $0.70 / \mathrm{kg}$ of glucose, due to its high cost.

No attempt was made to determine the optimal quantity of chemical used in this study. The low solubility of calcium hydroxide makes a direct comparison to sodium and potassium hydroxide difficult. If on-farm pretreatment strategies are considered, disposal of high sodium solids could be problematic relative to calcium or potassium hydroxide.

\section{CONCLUSION}

There was considerable variation in the performance of the alkaline sources in terms of lignin removal and cellulose conversion after pretreatment. With switchgrass, all three chemical pretreatments resulted in a significant decrease in lignin content, although potassium and sodium hydroxide provided a significantly greater delignification (30 to $37 \%$ ) than calcium hydroxide (13 to $21 \%$ ). The increase in cellulose and hemicellulose content due to pretreatment provided mixed results. In general, the cellulose and hemicellulose increased when switchgrass was pretreated at $50{ }^{\circ} \mathrm{C}$, but were not significantly altered when pretreated at $20^{\circ} \mathrm{C}$.

The composition changes in miscanthus after pretreatment with sodium and potassium hydroxide produced significantly greater delignification (32 to 47\%) at the two 
temperatures compared to calcium hydroxide that removed between (14 to 20\%). After pretreatment at $20^{\circ} \mathrm{C}$, the cellulose content significantly increased with all three chemicals. The cellulose content significantly increased and the hemicellulose decreased when pretreated at $50{ }^{\circ} \mathrm{C}$ with sodium and potassium hydroxide, but the other results were mixed.

Based on the Michaelis-Menten model for a batch reactor, the maximum reaction rate coefficient for potassium and sodium hydroxide at $20^{\circ} \mathrm{C}$ was statistically not different for switchgrass and was higher than calcium hydroxide. However, at $50{ }^{\circ} \mathrm{C}$, sodium hydroxide was significantly higher than potassium hydroxide and calcium hydroxide. There was no clear trend in the reaction rate based on temperature for switchgrass. With miscanthus, the maximum reaction rate increased by approximately $150 \%$ for sodium and potassium hydroxide when the temperature was increased. However, it decreased with calcium hydroxide when the temperature was increased.

As expected, the percentage of cellulose converted followed the trends in lignin removal and maximum reaction rate. Sodium and potassium hydroxide had a similar cellulose conversion for switchgrass pretreated at $20{ }^{\circ} \mathrm{C}(\sim 66 \%)$, miscanthus at $20{ }^{\circ} \mathrm{C}$ ( $62 \%)$, and miscanthus at $50{ }^{\circ} \mathrm{C}(\sim 78 \%)$. The exception was switchgrass pretreated at 50 ${ }^{\circ} \mathrm{C}$ where the conversion was $71 \%$ for sodium hydroxide, but decreased to $56 \%$ when pretreated with potassium hydroxide. In all cases, calcium hydroxide was statistically better than the controls, but lower than sodium or potassium hydroxide.

However, in order to make a fair comparison of effectiveness of calcium hydroxide, sodium hydroxide, and potassium hydroxide as pretreatment agents, pretreatment conditions compatible with all three alkali must be considered. Pretreatment conditions 
optimal for calcium hydroxide were not used in this study that lowered the effectiveness relative to sodium and potassium hydroxide.

\section{ACKNOWLEDGEMENTS}

The authors sincerely acknowledge the financial support of the United States Department of Agriculture National Institute for Food and Agriculture Biomass Research and Development Initiative Grant \#2011-10006-30363. This is publication No. 16-15-085 of the Kentucky Agricultural Experiment Station and is published with the approval of the Director. This work is supported by the National Institute of Food and Agriculture, U.S. Department of Agriculture, Hatch- Multistate under 1002344 and 1003563.

\section{REFERENCES}

Anderson, D.C., Ralston, A.T., 1973. Chemical treatment of ryegrass straw: in vitro dry matter digestibility and compositional changes. J Anim Sci 37.

Bales, G.L., Kellogg, D.W., Miller, D.D., 1979. Comparison of ammonium, potassium, sodium, chloride and hydroxyl ions on in vitro dry matter disappearance of milo stalks. J Anim Sci 49, 13241330.

Baral, N.R., Li, J., Jha, A.K., 2013. Perspective and prospective of pretreatment of corn straw for butanol production. Appl Biochem Biotech 172, 840-853.

Brown, R.C., 2003. Biorenewable Resources - Engineering New Products from Agriculture. Blackwell Publishing, Ames, IA.

Chang, V.S., Burr, B., Holtzapple, M.T., 1997. Lime pretreatment of switchgrass. Applied Biochemistry and Biotechnology 63-5, 3-19.

Chen, Y., Stevens, M.A., Zhu, Y., Holmes, J., Xu, H., 2013. Understanding of alkaline pretreatment parameters for corn stover enzymatic saccharification. Biotechnology for Biofuels 6, 1-10. Cheng, Y.S., Zheng, Y., Yu, C.W., Dooley, T.M., Jenkins, B.M., VanderGheynst, J.S., 2010. Evaluation of High Solids Alkaline Pretreatment of Rice Straw. Applied Biochemistry and Biotechnology 162, 1768-1784. 
Davidson, E.C., 1927. The treatment of acid and alkali burns: an experimental study. Ann Surg 85, 481-489.

de Vrije, T., de Haas, G.G., Tan, G.B., Keijsers, E.R.P., Claassen, P.A.M., 2002. Pretreatment of Miscanthus for hydrogen production by Thermotoga elfii. Int J Hydrogen Energy 27, 1381-1390. Dolk, M., Yan Johnson, F., McCarthy Joseph, L., 1989. Lignin 25. Kinetics of delignification of western hemlock in flow-through reactors under alkaline conditions, Holzforschung - International Journal of the Biology, Chemistry, Physics and Technology of Wood, p. 91.

Ge, X., Xu, F., Li, Y., 2016. Solid-state anaerobic digestion of lignocellulosic biomass: Recent progress and perspectives. Bioresource Technology 205, 239-249.

Heaton, E.A., Dohleman, F.G., Long, S.P., 2008. Meeting US biofuel goals with less land: the potential of Miscanthus. Glob Chang Biol 14, 2000-2014.

Jackson, J., Turner, A., Mark, T., Montross, M., 2016. Densification of biomass using a pilot scale flat ring roller pellet mill. Fuel Process Technol 148, 43-49.

Jackson, M.G., 1977. Review article: The alkali treatment of straws. Anim Feed Sci Tech 2, 105-130. Kaar, W.E., Holtzapple, M.T., 2000. Using lime pretreatment to facilitate the enzymic hydrolysis of corn stover. Biomass Bioenerg 18, 189-199.

Karp, E.M., Resch, M.G., Donohoe, B.S., Ciesielski, P.N., O’Brien, M.H., Nill, J.E., Mittal, A., Biddy, M.J., Beckham, G.T., 2015. Alkaline pretreatment of switchgrass. ACS Sustain Chem Eng 3, 14791491.

Kim, S., Holtzapple, M.T., 2005. Lime pretreatment and enzymatic hydrolysis of corn stover. Bioresour Technol 96, 1994-2006.

Kumar, P., Barrett, D.M., Delwiche, M.J., Stroeve, P., 2009. Methods for pretreatment of lignocellulosic biomass for efficient hydrolysis and biofuel production. Ind Eng Chem Res 48, 37133729.

Modenbach, A.A., Nokes, S.E., 2012. The use of high-solids loadings in biomass pretreatment-a review. Biotechnology and Bioengineering 109, 1430-1442.

Mosier, N., Wyman, C., Dale, B., Elander, R., Lee, Y.Y., Holtzapple, M., Ladisch, M., 2005. Features of promising technologies for pretreatment of lignocellulosic biomass. Bioresour Technol 96, 673686.

Nlewem, K.C., Thrash Jr, M.E., 2010. Comparison of different pretreatment methods based on residual lignin effect on the enzymatic hydrolysis of switchgrass. Bioresour Technol 101, 54265430.

Nokes, S.E., Lynn, B.C., Rankin, S., Knutson, B., Montross, M.D., Flythe, M., 2014. On-farm integrated high-solids processing system for biomass. Google Patents.

Ong, L., Chuah, C., Chew, A., 2010. Comparison of sodium hydroxide and potassium hydroxide followed by heat treatment on rice straw for cellulase production under solid state fermentation. J Appl Sci 10, 2608-2612.

Rounds, W., Klopfenstein, T., Waller, J., Messersmith, T., 1976. Influence of alkali treatments of corn cobs on in vitro dry matter disappearance and lamb performance. J Anim Sci 43.

Samuel, R., Foston, M., Jiang, N., Allison, L., Ragauskas, A.J., 2011. Structural changes in switchgrass lignin and hemicelluloses during pretreatments by NMR analysis. Polym Degrad Stab 96, 2002-2009.

Sharma, R., Palled, V., Sharma-Shivappa, R.R., Osborne, J., 2013. Potential of potassium hydroxide pretreatment of switchgrass for fermentable sugar production. Appl Biochem Biotech 169, 761772. 
Silverstein, R.A., Chen, Y., Sharma-Shivappa, R.R., Boyette, M.D., Osborne, J., 2007. A comparison of chemical pretreatment methods for improving saccharification of cotton stalks. Bioresour Technol 98, 3000-3011.

Sirohi, S.K., Rai, S.N., 1998. Optimisation of treatment conditions of wheat straw with lime: Effect of concentration, moisture content and treatment time on chemical composition and in vitro digestibility. Anim Feed Sci Tech 74, 57-62.

Varga, E., Szengyel, Z., Reczey, K., 2002. Chemical pretreatments of corn stover for enhancing enzymatic digestibility. Appl Bioch and Biotech 98-100, 73-87.

Winugroho, M., Ibrahim, M.N.M., Pearce, G.R., 1984. A soak-and-press method for the alkali treatment of fibrous crop residues - Calcium hydroxide and sodium-hydroxide treatments of rice straw. Agr Wastes 9, 87-99.

Xu, J., Cheng, J.J., Sharma-Shivappa, R.R., Burns, J., C., 2010a. Lime pretreatment of switchgrass at mild temperatures for ethanol production. Bioresour Technol 101, 2900 - 2903.

Xu, J., Cheng, J.J., Sharma-Shivappa, R.R., Burns, J.C., 2010b. Sodium hydroxide pretreatment of switchgrass for ethanol production. Energ Fuel 24, 2113-2119.

Yang, D., 2009. Pretreatment of rice straw for increasing the biodegradability. University of California, Davis, United States -- California, p. 105.

Zheng, Y., Pan, Z., Zhang, R., 2009. Overview of biomass pretreatment for cellulosic ethanol production. Int J Agric Biol Eng 2, 51-68. 
Table 1. Comparison of sodium, potassium, and calcium hydroxide based on $\% \mathrm{OH}$ concentration by mass ${ }^{1}$, $\mathrm{pH}^{\mathrm{of}}$ $1 \%$ solution ${ }^{1}$, and estimated cost.

\begin{tabular}{lccc}
\hline Property & $\begin{array}{c}\text { Sodium } \\
\text { hydroxide }\end{array}$ & $\begin{array}{c}\text { Potassium } \\
\text { hydroxide }\end{array}$ & $\begin{array}{c}\text { Calcium } \\
\text { hydroxide }\end{array}$ \\
\hline $\begin{array}{l}\text { Molecular Formula } \\
\text { Molecular Weight }\end{array}$ & $\mathrm{NaOH}$ & $\mathrm{KOH}$ & $\mathrm{Ca}(\mathrm{OH})_{2}$ \\
$(\mathrm{~g} / \mathrm{mol})$ & 39.998 & 56.106 & 74.092 \\
$\%$ OH by mass & $42.5 \%$ & $30.4 \%$ & $45.9 \%$ \\
$\mathrm{pH}(1 \%$ solution $)$ & 12.7 & 13.7 & 12.4 \\
Cost $(\$ / \mathrm{Mg})$ & $\$ 507^{2}$ & $\$ 1100^{3}$ & $\$ 385^{4}$ \\
\hline
\end{tabular}

'developed from MSDS from Santa Cruz Biotechnology, Inc. Santa

Cruz, CA 95060 USA and PubChem http://pubchem.ncbi.nlm.nih.gov

${ }^{2}$ http://www.alibaba.com/showroom/bulk-sodium-hydroxide.html

${ }^{3} \mathrm{http}: / /$ www.alibaba.com/trade/potassium+hydroxide+price

${ }^{4} \mathrm{http}: / /$ magissues.farmprogress.com/BeefProducer/BP11Nov12/bp04.pdf 
Table 2. Average composition and standard deviation of unextracted raw switchgrass and miscanthus. (Average of three replications).

\begin{tabular}{lcc} 
& \multicolumn{2}{c}{ Dry Weight $(\%)$} \\
Component & Switchgrass & Miscanthus \\
\hline Acid Soluble Lignin & $2.0 \pm 0.15$ & $1.3 \pm 0.03$ \\
Acid Insoluble Lignin & $27.8 \pm \mathbf{0 . 5 1}$ & $\mathbf{3 0 . 9} \pm \mathbf{0 . 6 1}$ \\
Cellulose & $44.4 \pm \mathbf{3 . 7 0}$ & $\mathbf{4 5 . 7} \pm \mathbf{4 . 7 9}$ \\
Hemicellulose & $22.8 \pm 3.19$ & $19.6 \pm 0.90$ \\
Ash & $1.0 \pm \mathbf{0 . 1 4}$ & $2.9 \pm 0.56$ \\
Mass balance & $\mathbf{9 8 . 0} \pm \mathbf{4 . 9 2}$ & $\mathbf{1 0 0 . 4} \pm \mathbf{4 . 9 4}$ \\
\hline
\end{tabular}


Table 3. Estimated cost per $\mathrm{kg}$ of glucose $(\$ / \mathrm{kg})$ considering only pretreatment chemical cost (from Table 1) based on the measured glucose yields for switchgrass and miscanthus pretreated at 20 and $50{ }^{\circ} \mathrm{C}$.

\begin{tabular}{lcccc} 
& \multicolumn{2}{c}{ Switchgrass } & \multicolumn{2}{c}{ Miscanthus } \\
Pretreatment & $20{ }^{\circ} \mathrm{C}$ & $\mathbf{5 0}{ }^{\circ} \mathrm{C}$ & $\mathbf{2 0}^{\circ} \mathrm{C}$ & $\mathbf{5 0}{ }^{\circ} \mathrm{C}$ \\
\hline $\mathrm{Ca}(\mathrm{OH})_{2}$ & $\mathbf{0 . 1 8}$ & $\mathbf{0 . 2 5}$ & $\mathbf{0 . 3 0}$ & $\mathbf{0 . 4 5}$ \\
$\mathrm{NaOH}$ & $\mathbf{0 . 1 9}$ & $\mathbf{0 . 1 6}$ & $\mathbf{0 . 1 6}$ & $\mathbf{0 . 1 1}$ \\
$\mathrm{KOH}$ & $\mathbf{0 . 7 0}$ & $\mathbf{0 . 6 9}$ & $\mathbf{0 . 6 8}$ & $\mathbf{0 . 4 5}$ \\
\hline
\end{tabular}


Figure 1. Change in lignin, cellulose, and hemicellulose content for the raw switchgrass, three pretreatments and control (water) at $20^{\circ} \mathrm{C}$ and $50{ }^{\circ} \mathrm{C}$. Error bars are the standard deviation of three replications and treatments with the same letter are not statistically significant different based on Tukey's correction test at a significance level of 5\%.

Figure 2. Change in lignin, cellulose, and hemicellulose content for the raw miscanthus, three pretreatments and control (water) at $20^{\circ} \mathrm{C}$ and $50^{\circ} \mathrm{C}$. Error bars are the standard deviation of three replications and treatments with the same letter are not statistically significant different based on Tukey's correction test at a significance level of $5 \%$.

Figure 3. Solids recovery (\% by dry weight) after pretreatment from the three alkaline chemicals at $20{ }^{\circ} \mathrm{C}$ and $50{ }^{\circ} \mathrm{C}$ for switchgrass and miscanthus. Error bars are the standard deviation of three replications and treatments with the same letter are not statistically significant based on Tukey's correction test at a significance level of 5\%.

Figure 4. Cellulose digested after enzymatic hydrolysis of untreated, water pretreated and the three alkaline chemicals for (a) switchgrass at $20{ }^{\circ} \mathrm{C}$, (b) switchgrass at $50{ }^{\circ} \mathrm{C}$, (c) miscanthus at $20{ }^{\circ} \mathrm{C}$, and (d) miscanthus at $50{ }^{\circ} \mathrm{C}$. Error bars are the standard deviations of three replications.

Figure 3. Maximum reaction rate of cellulose digestion for the raw biomass, three pretreatments and control (water) at $20{ }^{\circ} \mathrm{C}$ and $50{ }^{\circ} \mathrm{C}$. Error bars are the standard deviation of three replications and treatments with the same letter are not statistically significant based on Tukey's correction test at a significance level of $5 \%$.

Figure 4. Cellulose conversion efficiency (\% by dry weight) after 72 hours of enzymatic hydrolysis for the raw biomass, three alkaline pretreatments and control (water) at $20{ }^{\circ} \mathrm{C}$ and $50{ }^{\circ} \mathrm{C}$. Error bars are the standard deviation of three replications and treatments with the same letter are not statistically significant based on Tukey's correction test at a significance level of $5 \%$. 


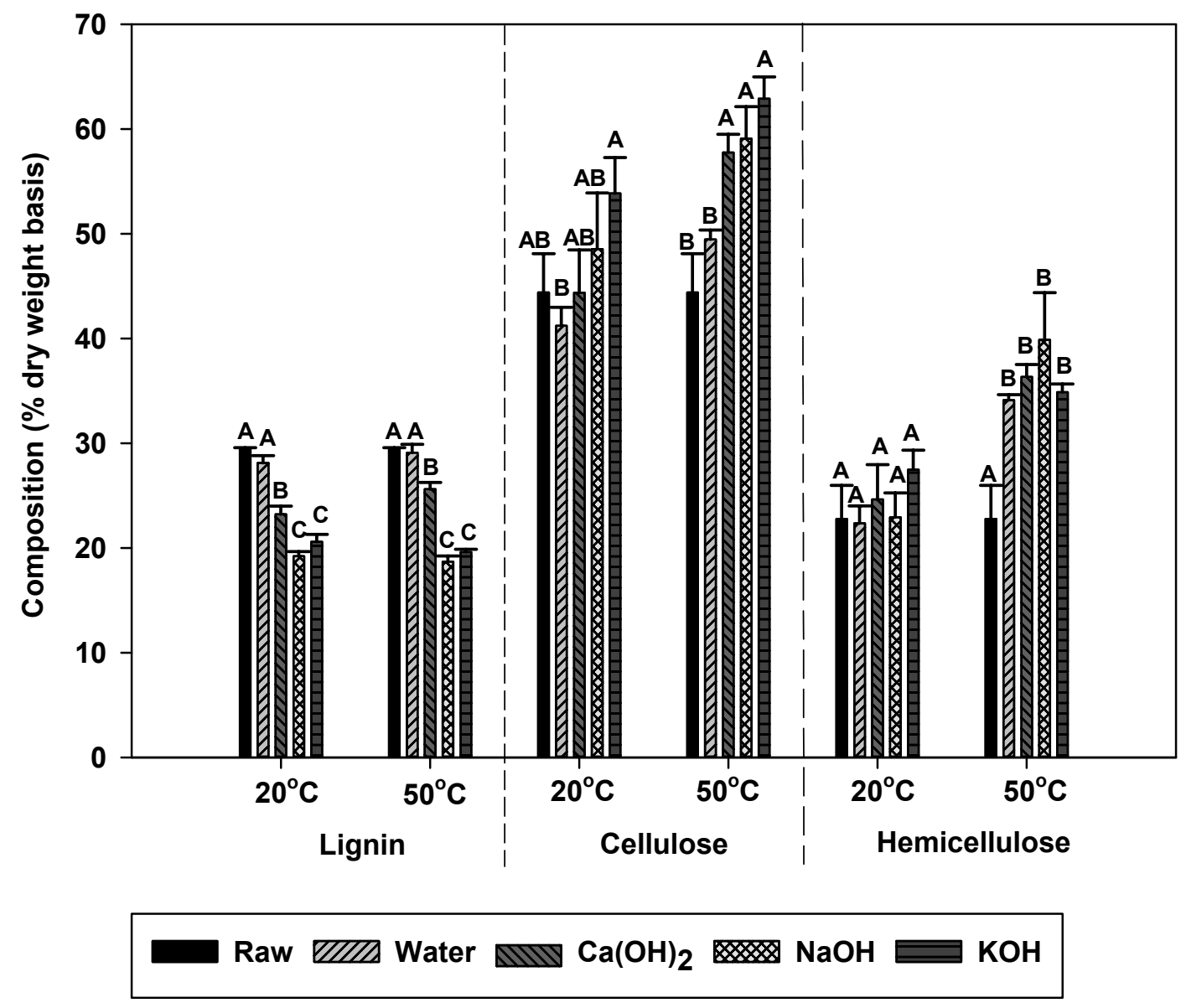




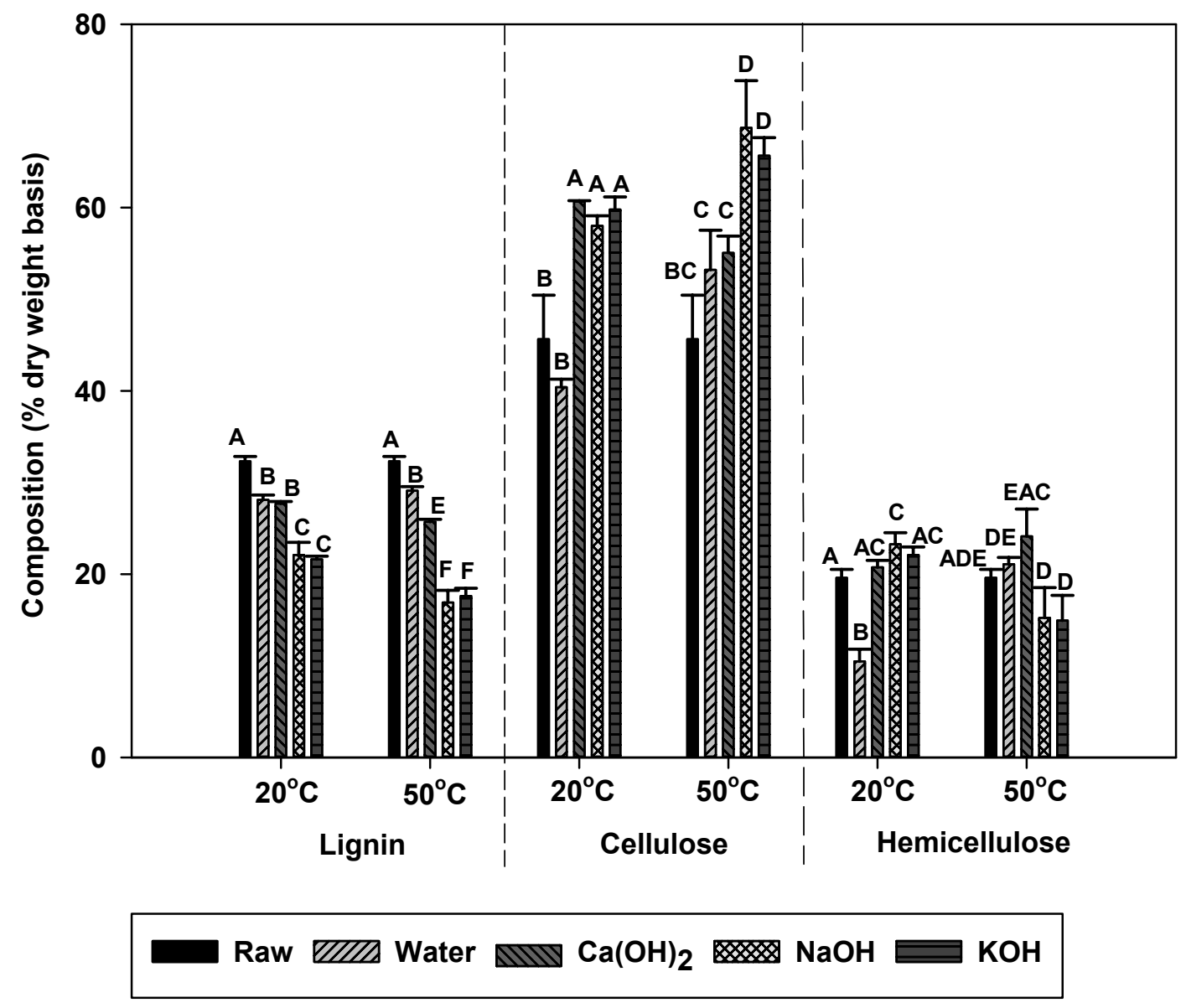




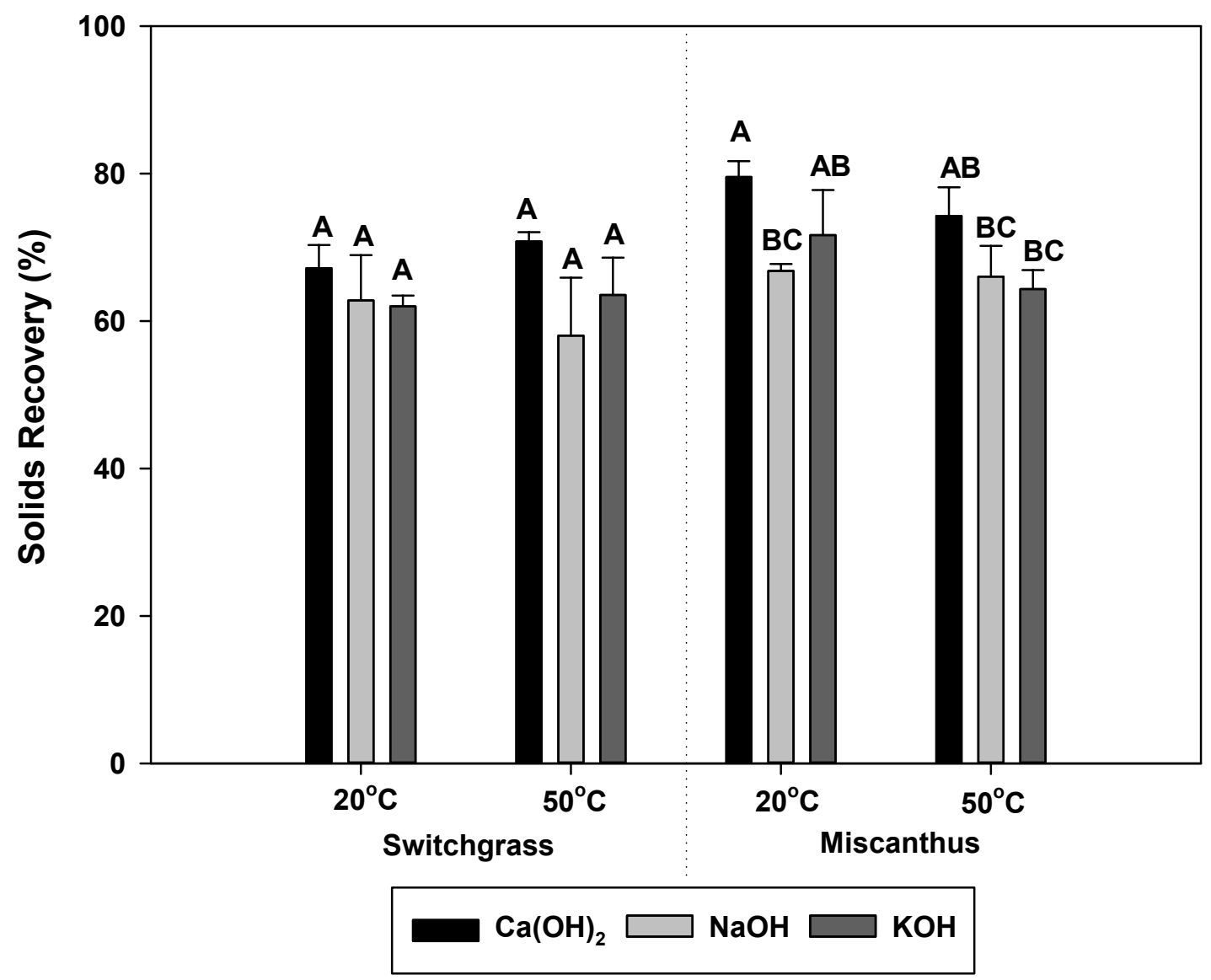




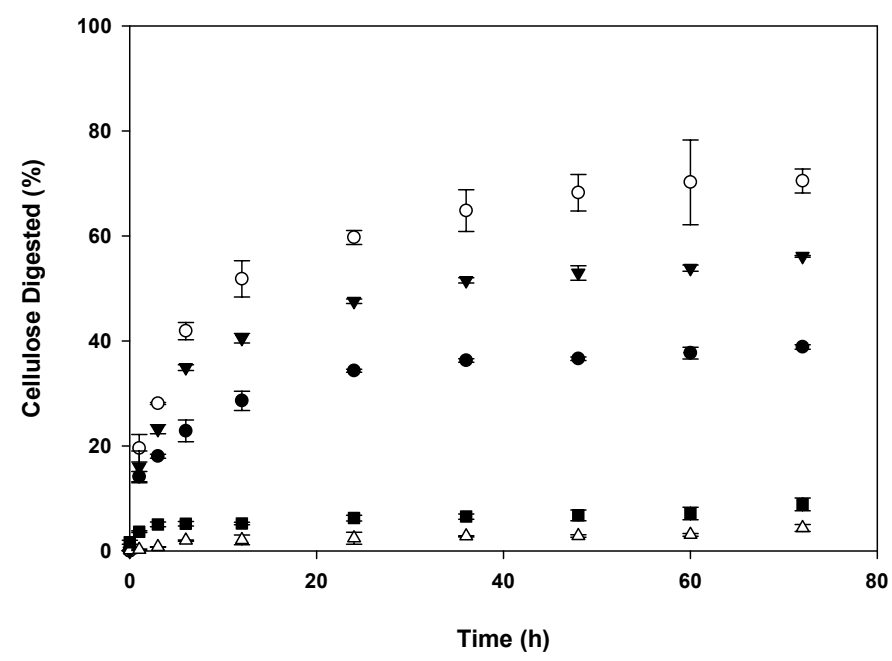

(a)

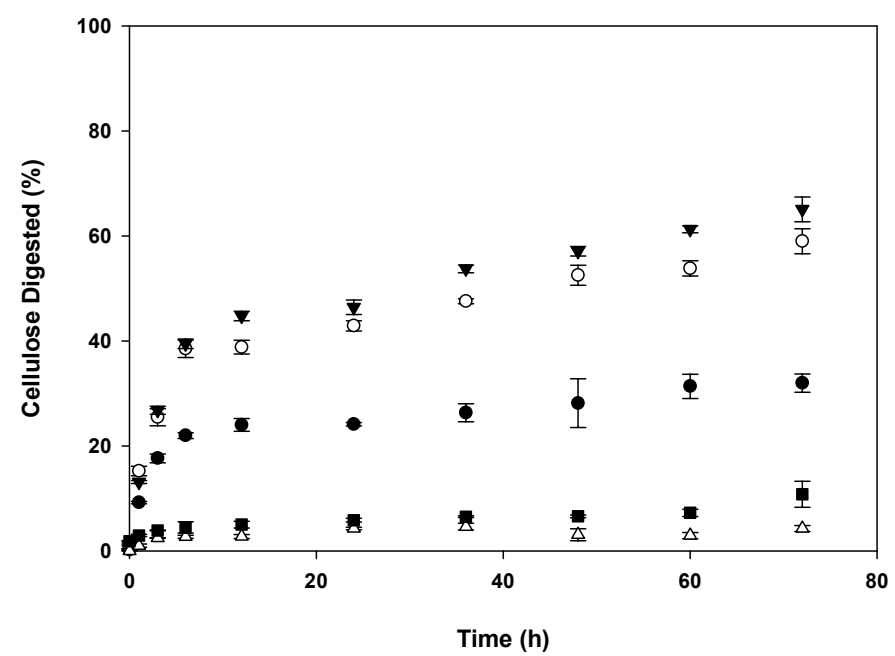

(c)

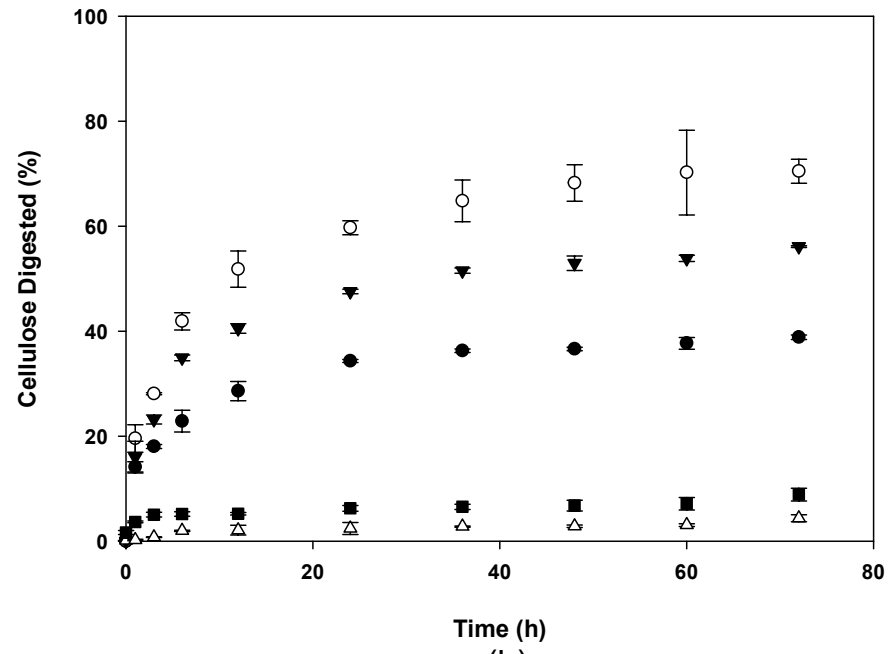

(b)

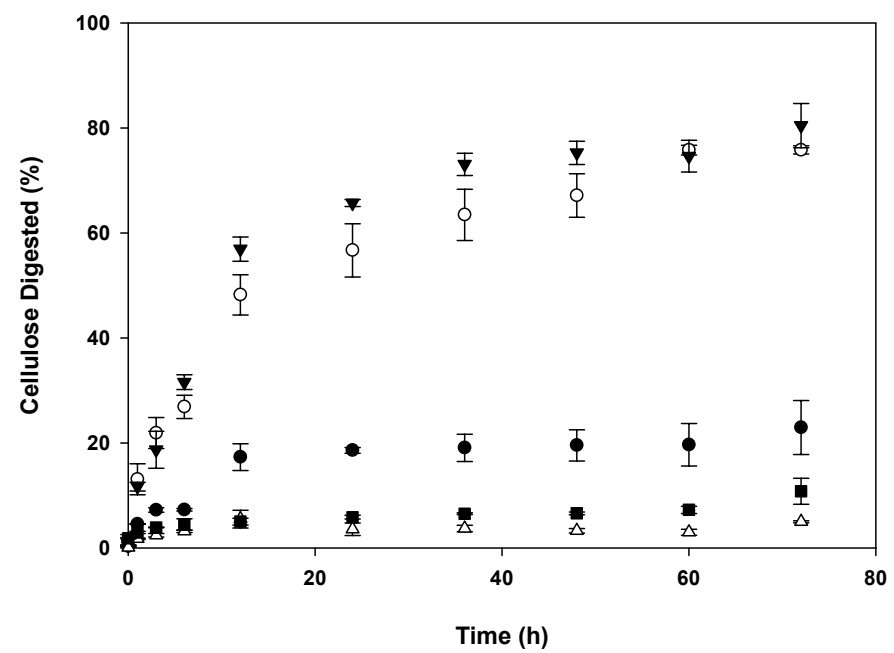

(d)

\section{- $\mathrm{Ca}(\mathrm{OH})_{2} \circ \mathrm{NaOH} \quad \mathrm{KOH} \triangle$ Water - Raw}




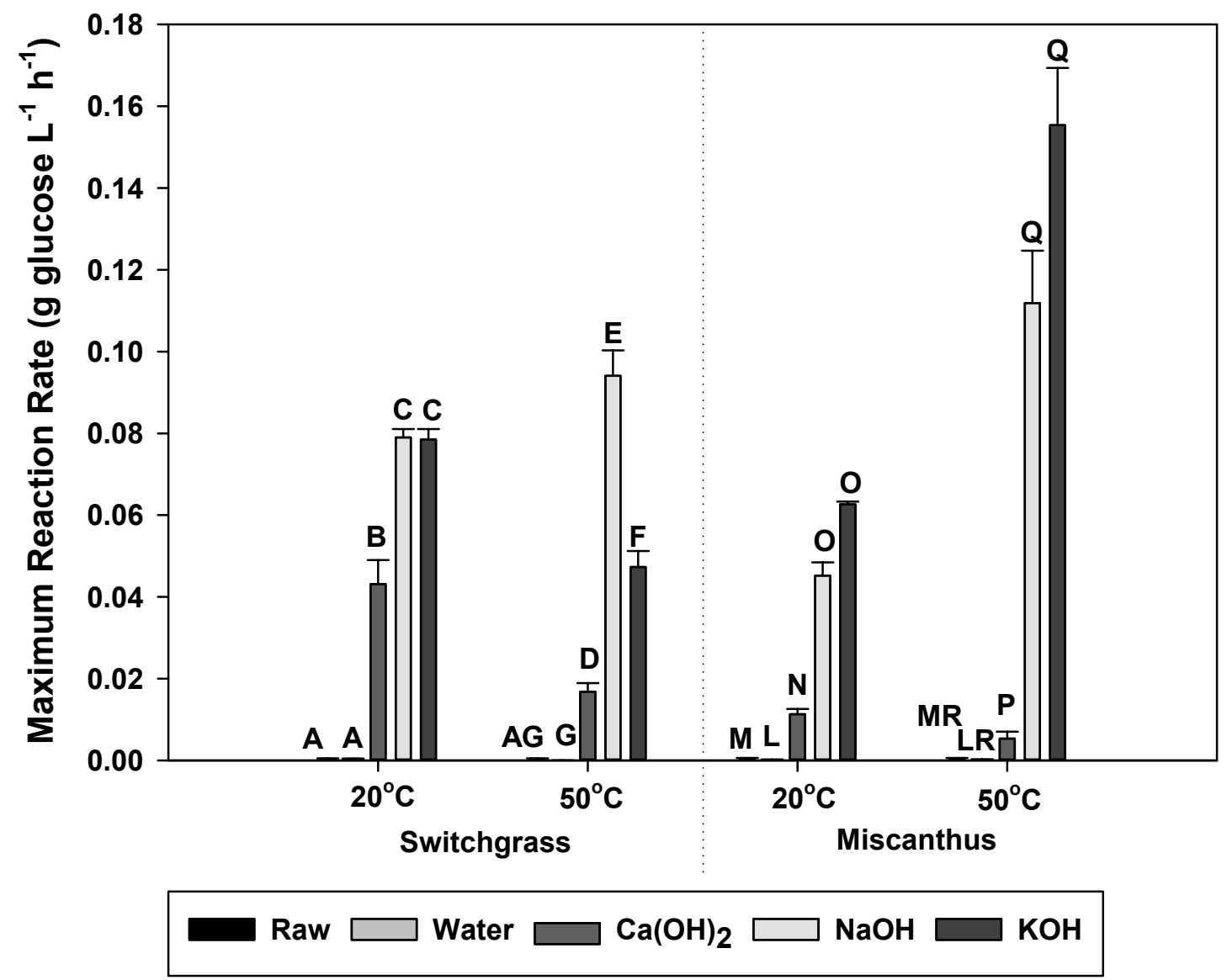




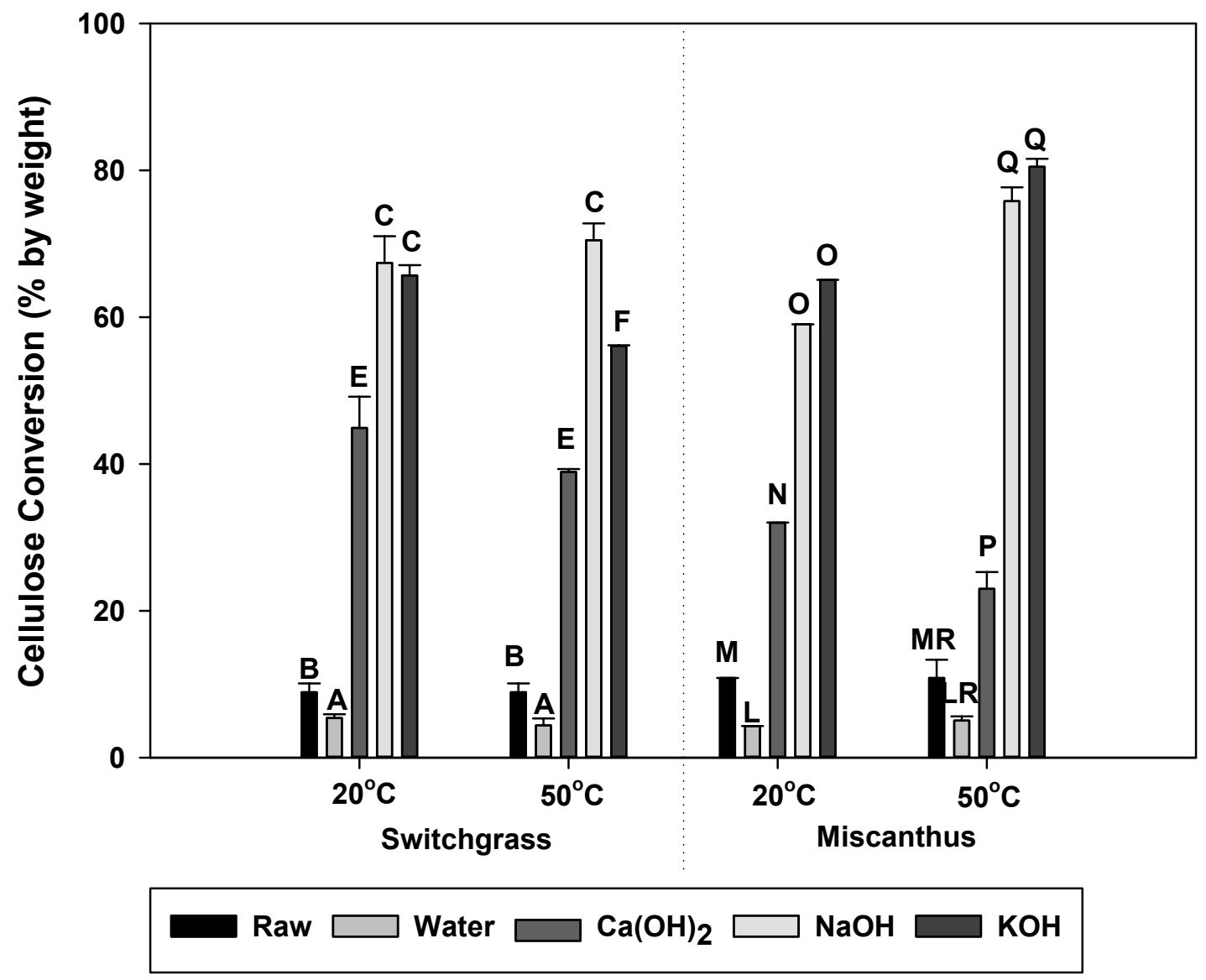

